\title{
The Influence of Past Decision Information on Decision Making in the Present
}

\section{Farzaneh Olianezhad $^{1,2}$, Sajjad Zabbah², Reza Ebrahimpour ${ }^{3^{*}}$}

${ }^{1}$ Faculty of Electrical Engineering, Shahid Rajaee Teacher Training University, Tehran, Iran

${ }^{2}$ School of Cognitive Sciences, Institute for Research in Fundamental Sciences (IPM), Tehran, Iran

${ }^{3}$ Faculty of Computer Engineering, Shahid Rajaee Teacher Training University, Tehran, Iran

\section{A BSTRACT}

Introduction: Decision process is an accumulation-to-bound mechanism, in which momentary sensory evidence is accumulated over time toward a criterion level. This bounded evidence accumulation is represented in the activity of neurons in the lateral intraparietal (LIP) cortex. Whether the firing rate of LIP neuron contains post decision information (PDI) or returns to baseline level as soon as decision made needs to be clarified. Materials and Methods: To investigate this issue, we conducted behavioral experiments based on the two forced-choice discrimination of motion direction. Human subjects reported the net direction of stochastic random dot motion by pressing a key of specified keys associated with the two possible directions of motion. Trials were separated by different time gaps. Results: Results showed that there is a preference in subjects to make a same decision as their pervious decision, especially in weak stimuli. Conclusion: Our findings suggest that the value of decision variable (DV) after crossing the bound (named PDI) may accumulate with DV for the next decisions.

\section{Key words:}

1. Decision Making

2. Psychophysics

3. Neurosciences

*Corresponding Author: Reza Ebrahimpour

E-mail: rebrahimpour@srttu.edu 


\title{
تأثير اطلاعات تصميم بيشين بر تصميمَيرى در زمان حاضر
}

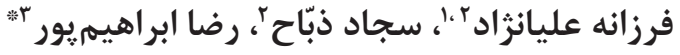 \\ 'دانشكده مهندسى برق، دانشخاه تربيت دبير شهيد رجايى، تهران، ايران \\ 'يزووهشكده علوم شناختى، يزوهشعاه دانش هاى بنيادى، تهران، ايران

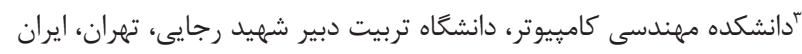

\section{Q}

مقدمه: فرايند تصميمَيرى يك سازوكار جمعآورى تا حد آستانه است، كه شواهد حسى لحظه

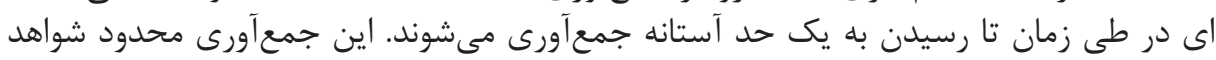

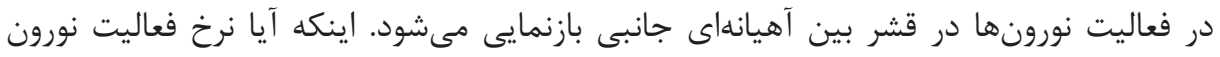

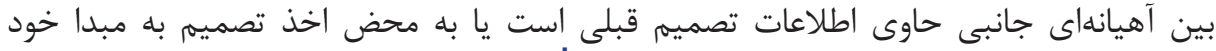

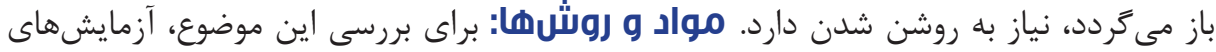

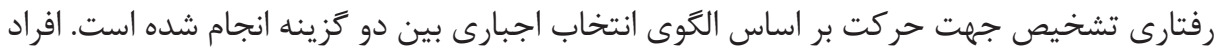

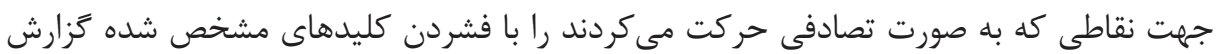

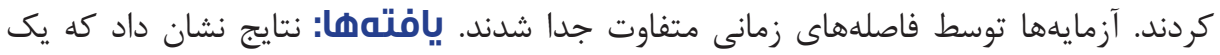

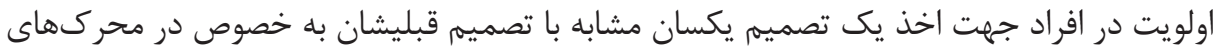

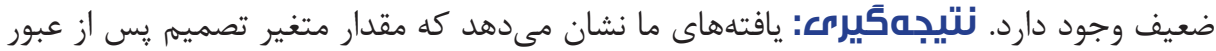

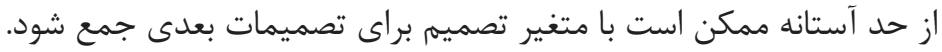

كليد وازهها:

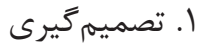

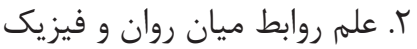

r. (ז. علوم اعصاب

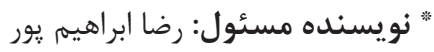
آدرس الكترونيكى: rebrahimpour@srttu.edu 


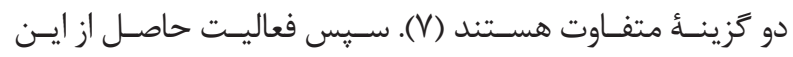

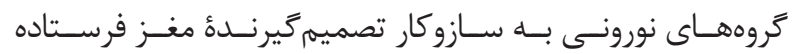

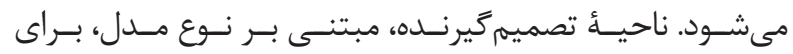

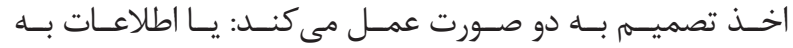

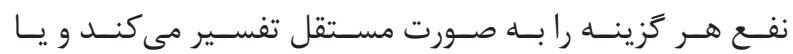

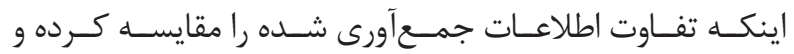

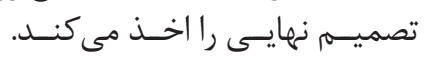

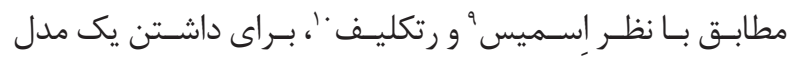

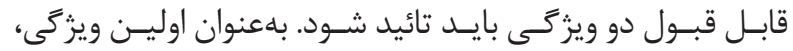

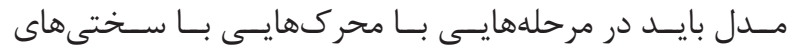

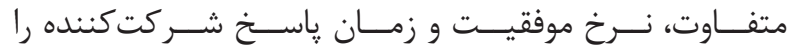

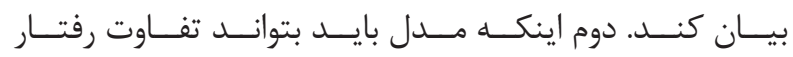

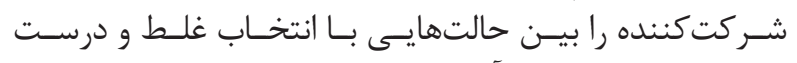

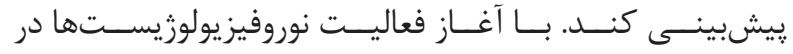

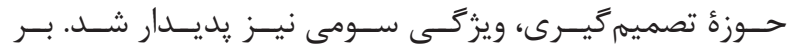

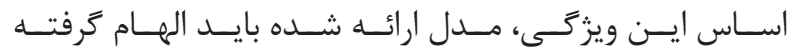

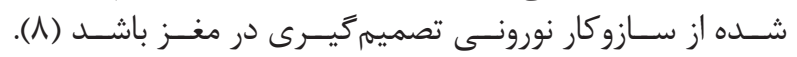

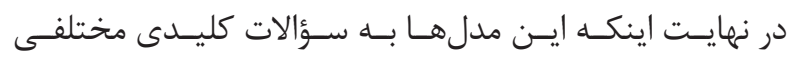

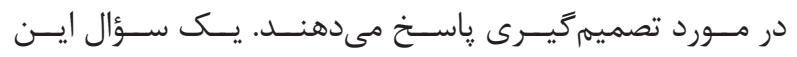

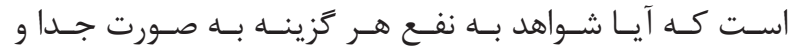

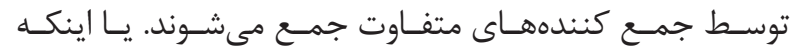

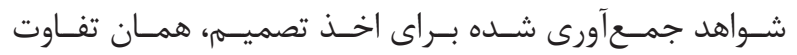

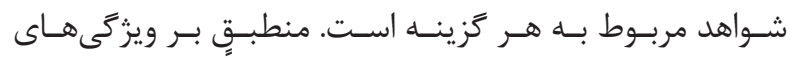

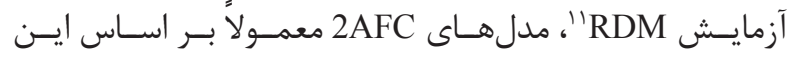

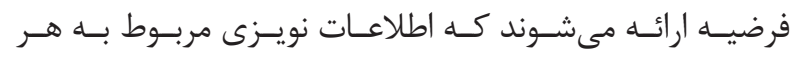

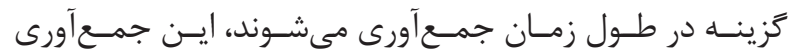

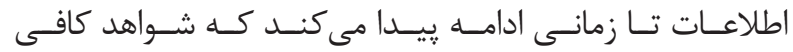

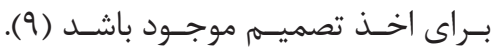

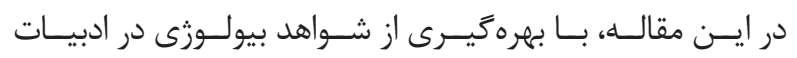

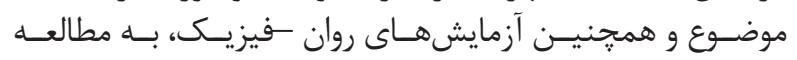

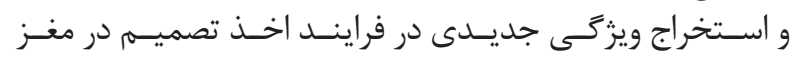

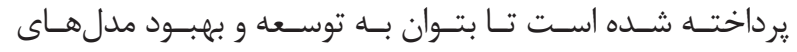

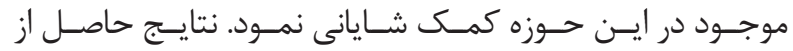

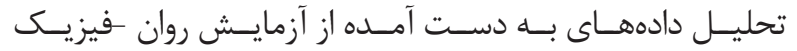

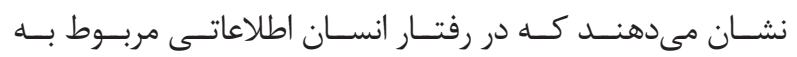

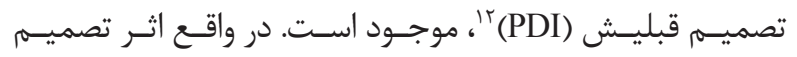

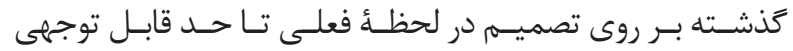

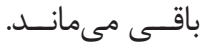

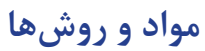

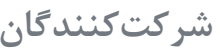

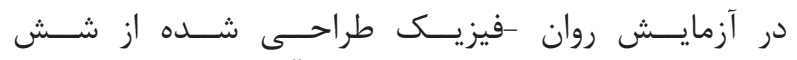

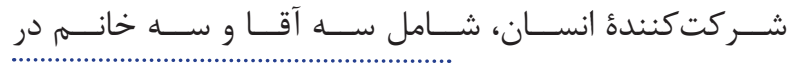

${ }^{1}$ Lateral intra-parietal

${ }^{2}$ Base line

${ }^{3}$ Two alternative forced choice

${ }^{4}$ Targets

${ }^{5}$ Diffusion

${ }^{6}$ Bogacz

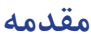

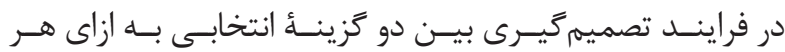

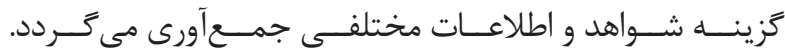

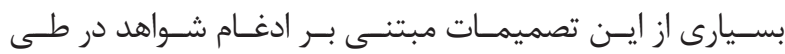

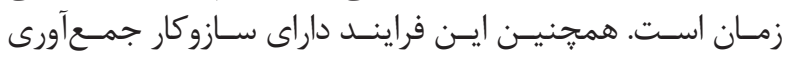

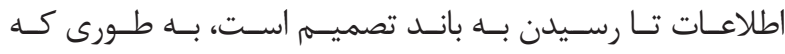

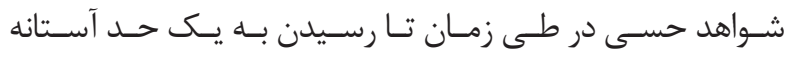

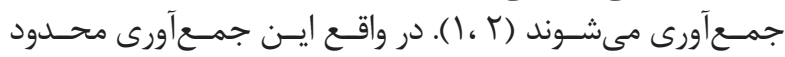

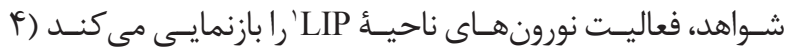

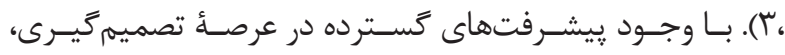

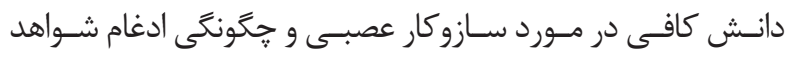

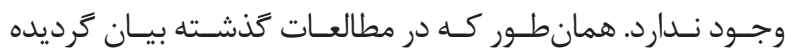

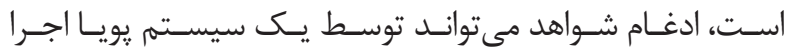

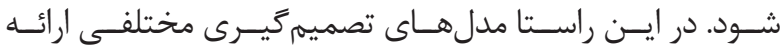

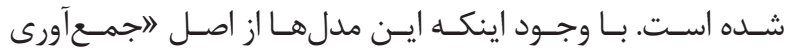

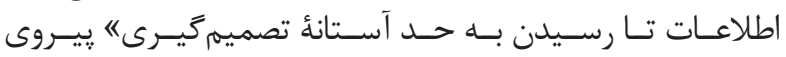

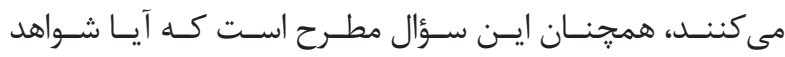

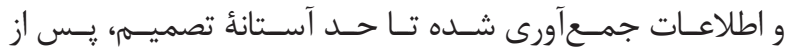

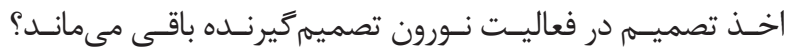

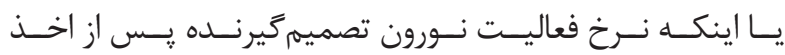

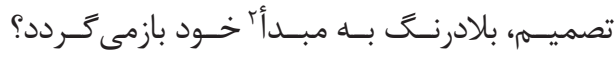

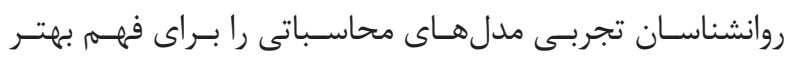

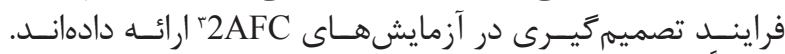

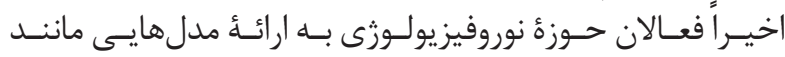

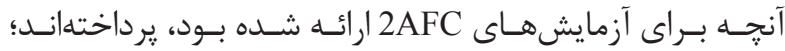

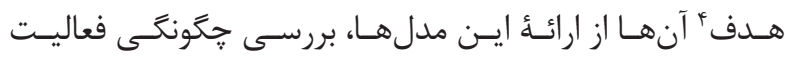

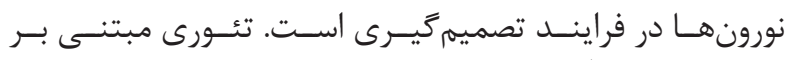

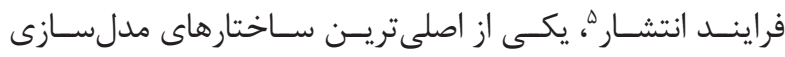

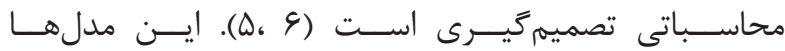

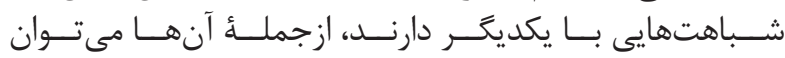

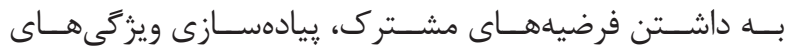

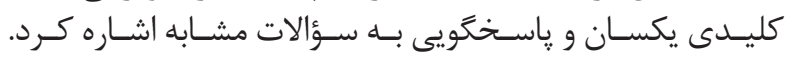

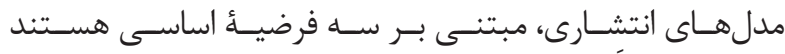

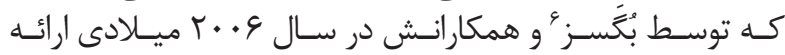

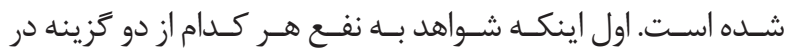

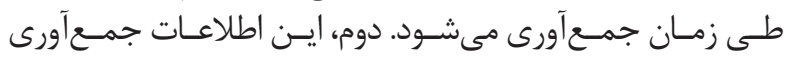

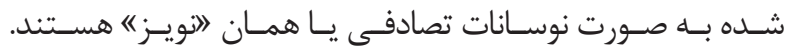

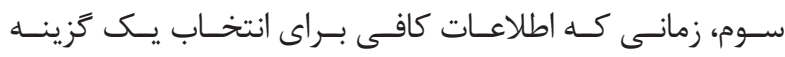

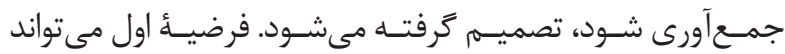

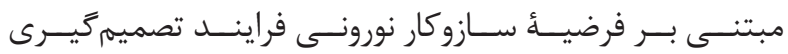

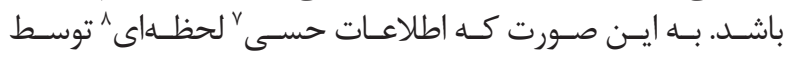

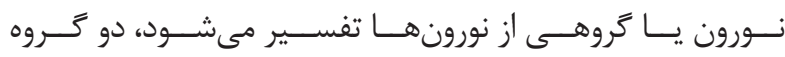

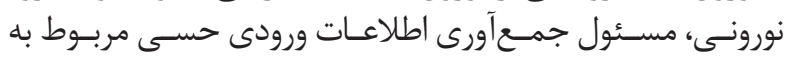

${ }^{7}$ Sensory

${ }^{8}$ Momentary

${ }^{9}$ Smith

${ }^{10}$ Ratcliff

${ }^{11}$ Random dot motion

${ }^{12}$ Post decision information 


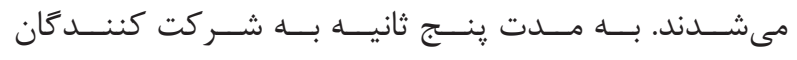

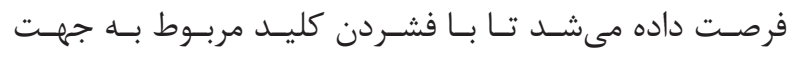

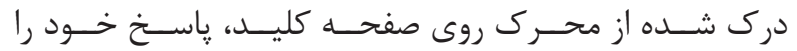

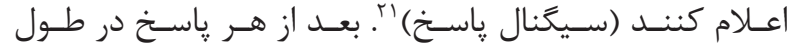

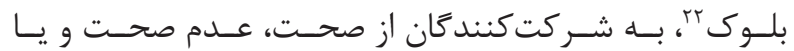

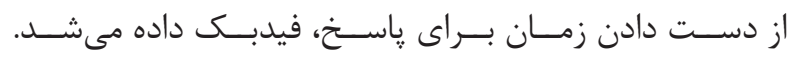

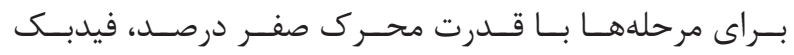

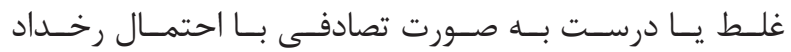

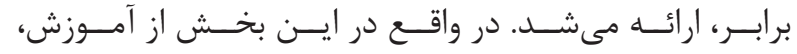

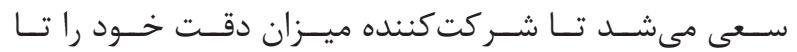

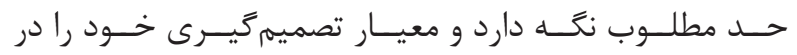

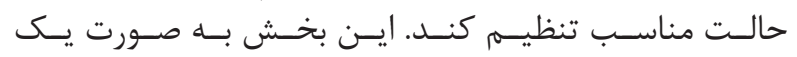

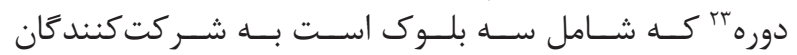

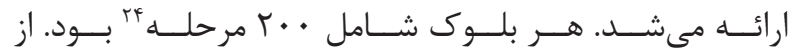

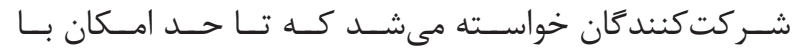

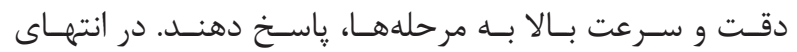

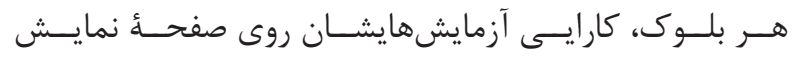

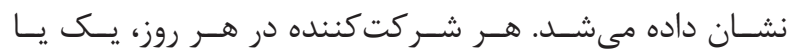

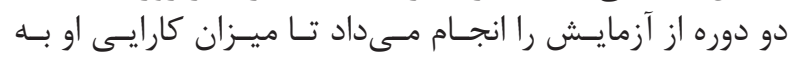

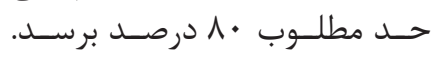
بخش آموزش زمان ياسخدهى مصن

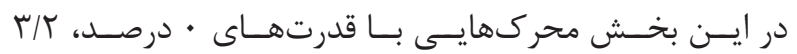

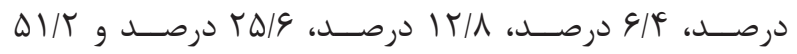

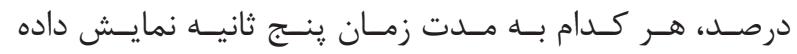

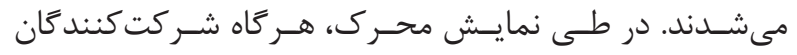

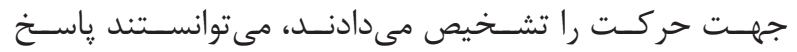

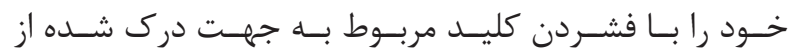

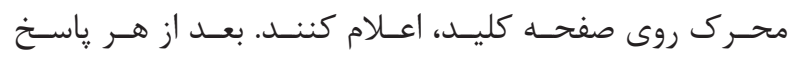

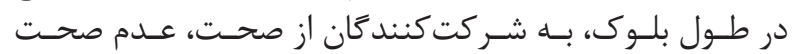

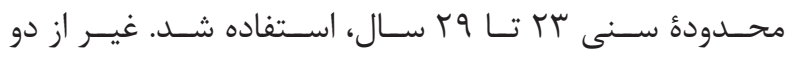

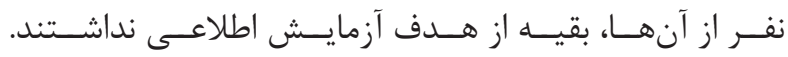

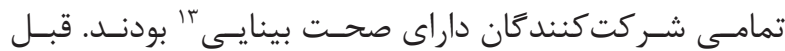

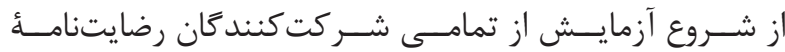

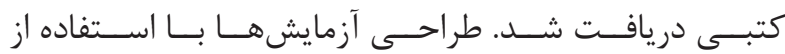

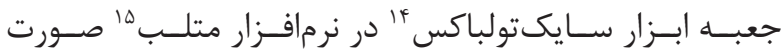

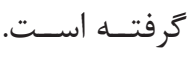
بخش آموزش

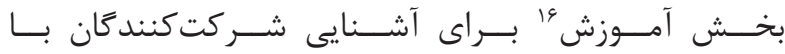

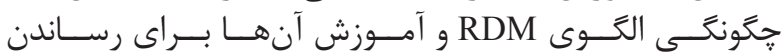

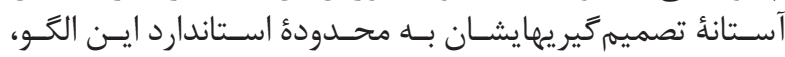

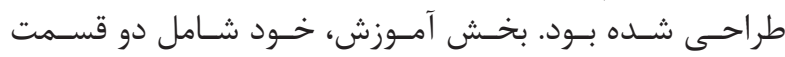

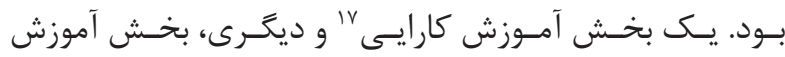

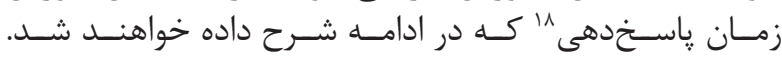

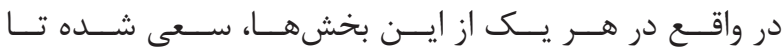

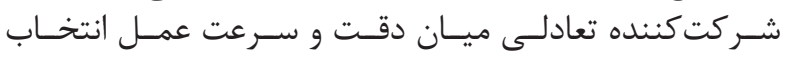

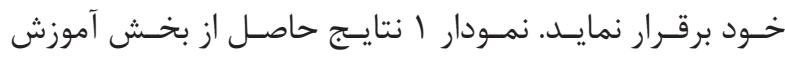

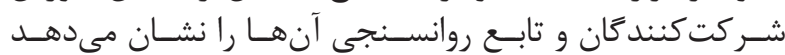

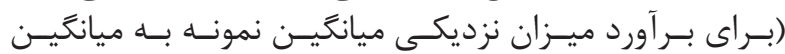

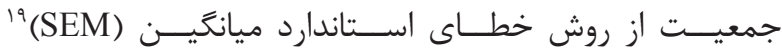

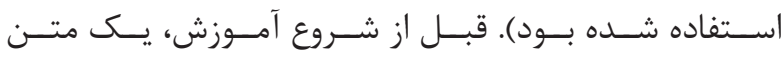

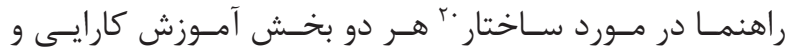

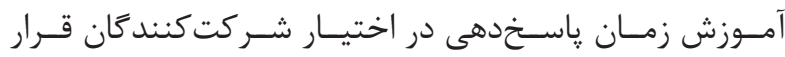
داده مى شــــد. بخش آموزش كارايى

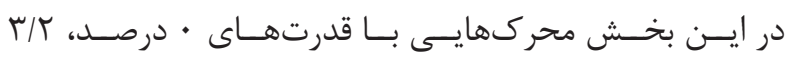

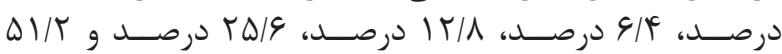

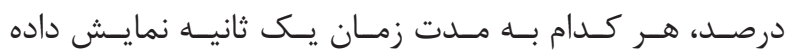
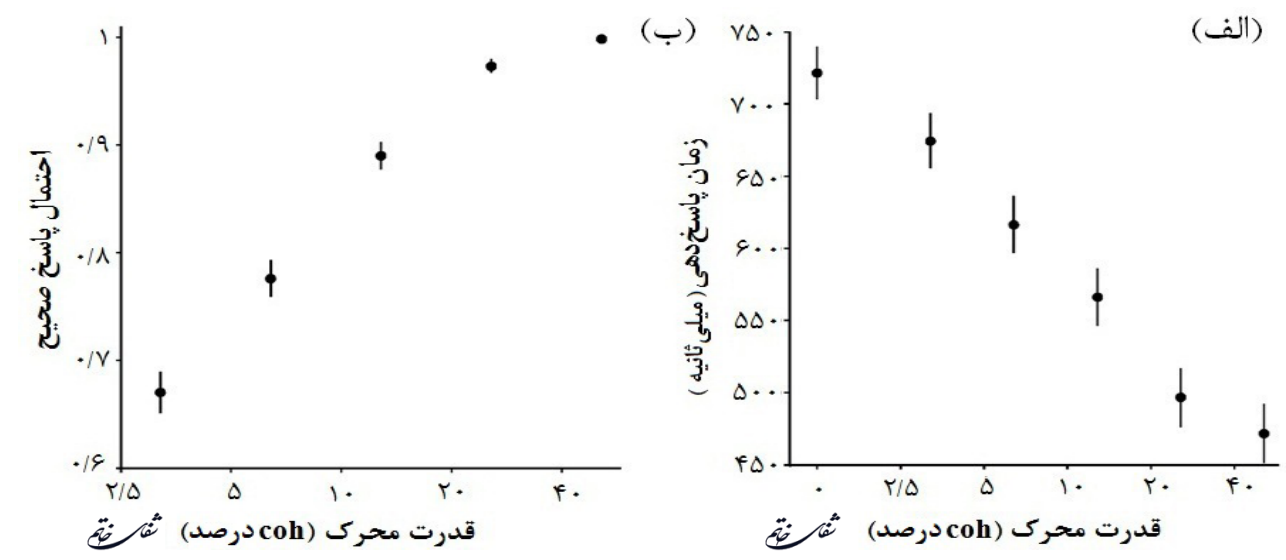

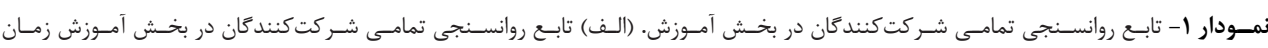

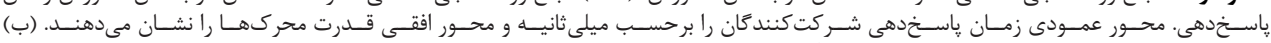

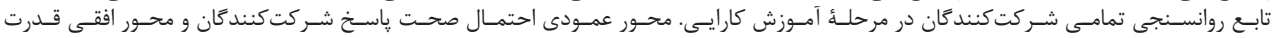

\footnotetext{
${ }^{13}$ Corrected-to-normal vision

${ }^{14}$ Psychtoolbox

${ }^{15}$ Mat lab

${ }^{16}$ Training phase

${ }^{17}$ Performance

${ }^{18}$ Reaction time
}

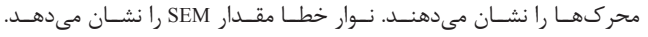

${ }^{19}$ Standard error of the mean

${ }^{20}$ Task structure

${ }^{21}$ Go signal

22 Block

${ }^{23}$ Session

24 Trial 


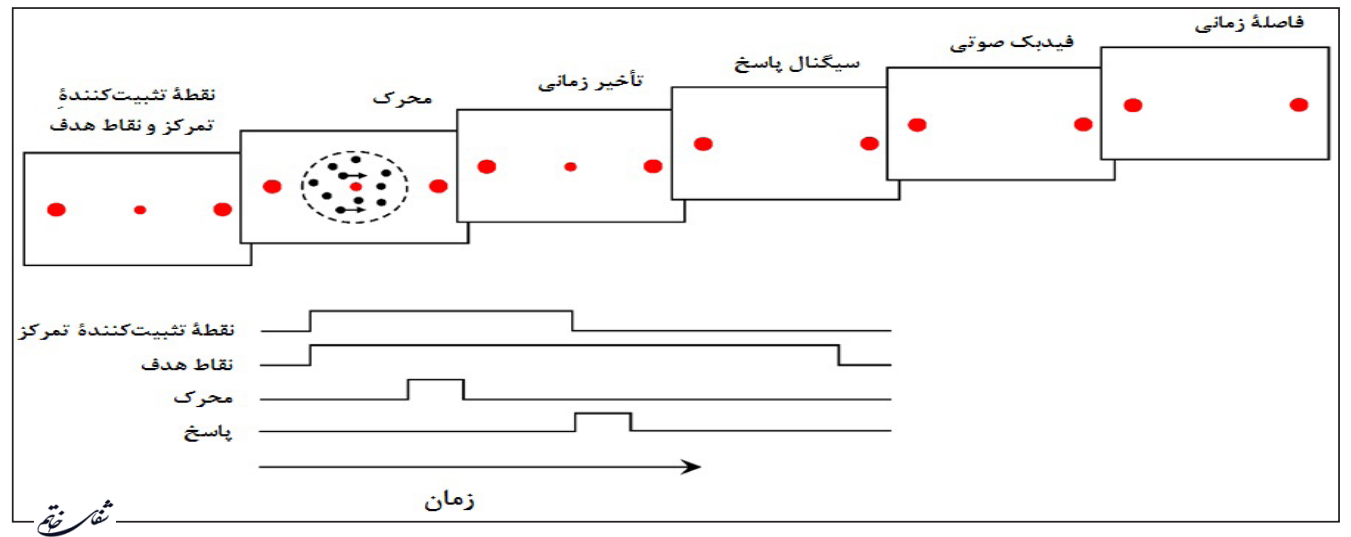

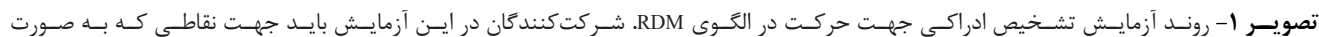

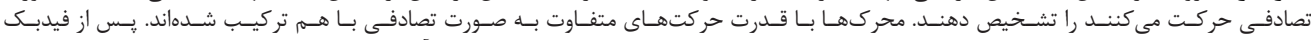

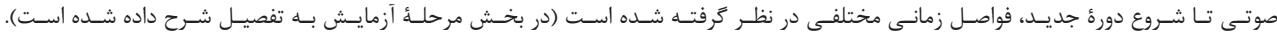

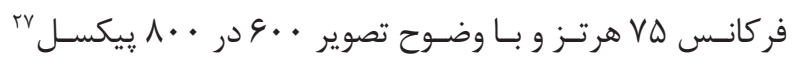

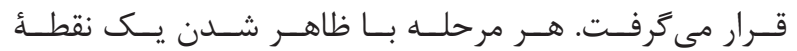

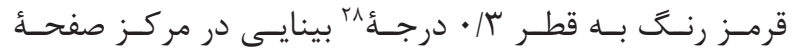

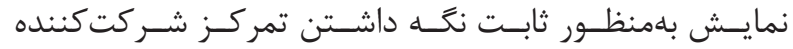

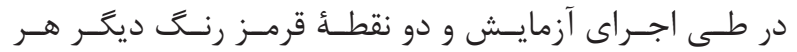

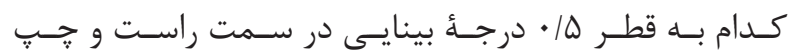

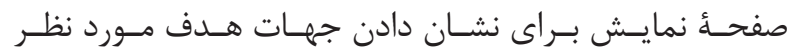

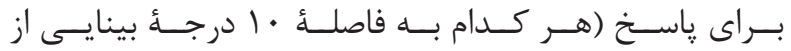

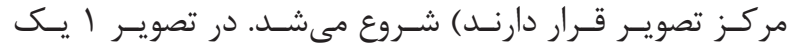

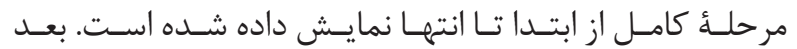

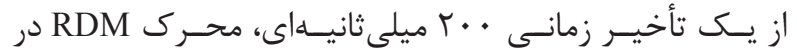

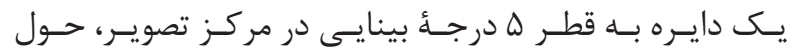

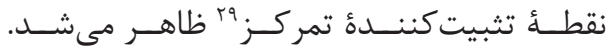

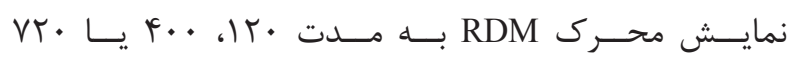

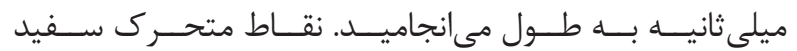

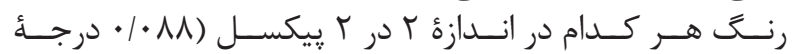

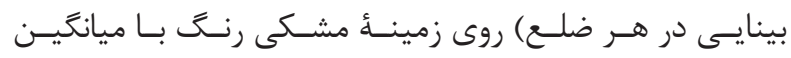

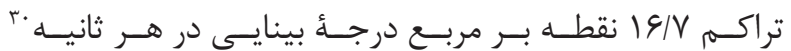

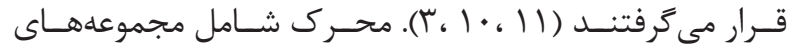

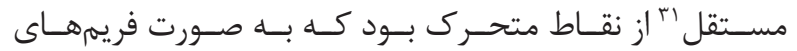

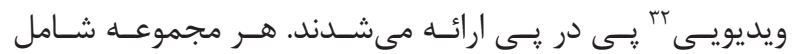

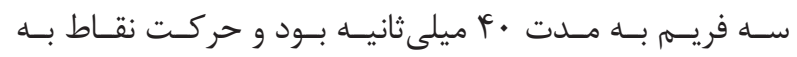

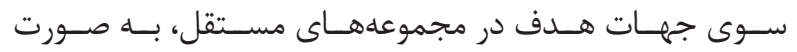

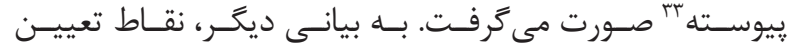

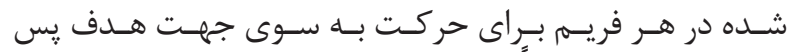

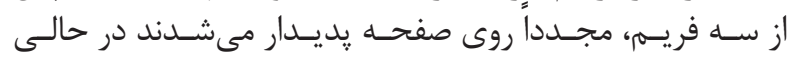

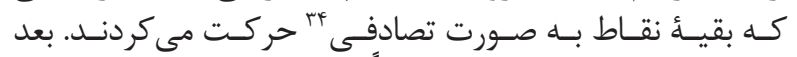

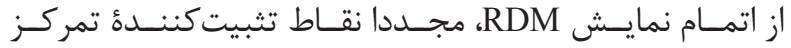

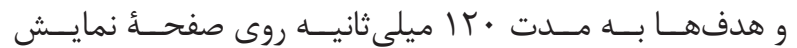

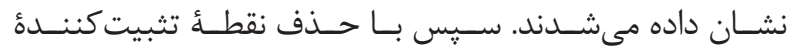

${ }^{25}$ Cathode ray tube

${ }^{26}$ Inch

${ }^{27}$ Pixel

${ }^{28}$ Angle

${ }^{29}$ Fixation point

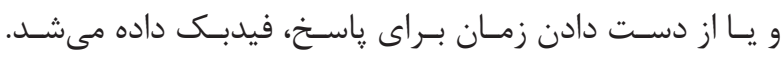

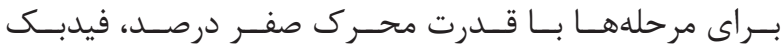

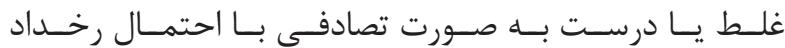

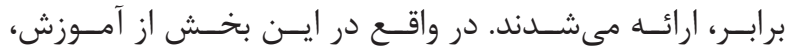

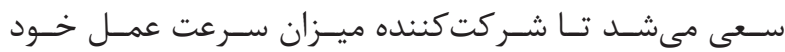

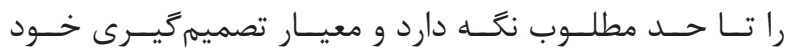

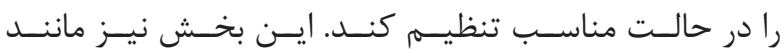

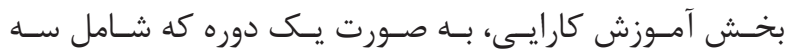

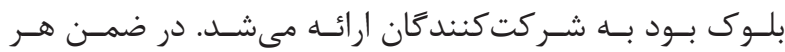

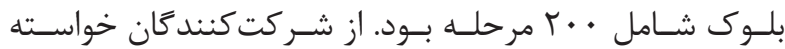

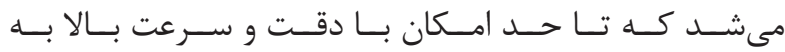

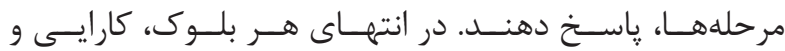

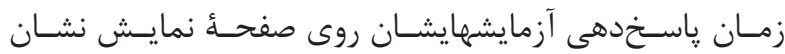

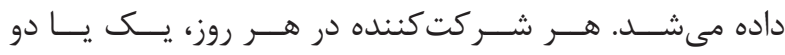

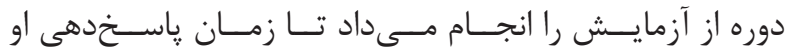

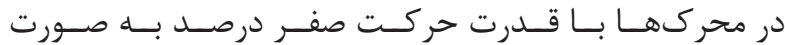

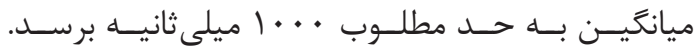

$$
\text { بخش آزمايش اصلى }
$$

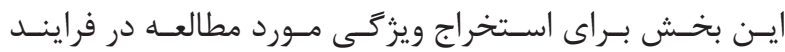

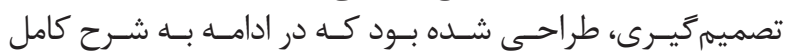

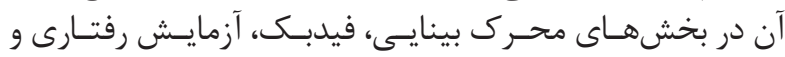

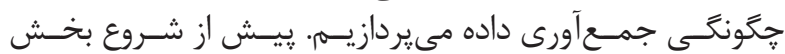

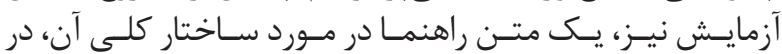

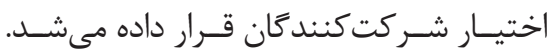

$$
\text { محرك بينايى }
$$

آزمايــش در يــك اتـاق نيمـــه تاريــــ و ايزولــهـ شـــده در

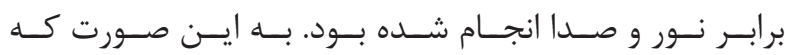

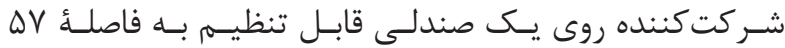

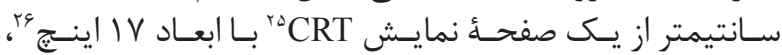

\footnotetext{
${ }^{30}$ Dots/degree2/s

${ }^{31}$ Independent sets

${ }^{32}$ Video frames

${ }^{33}$ Coherently

${ }^{34}$ Randomly
} 


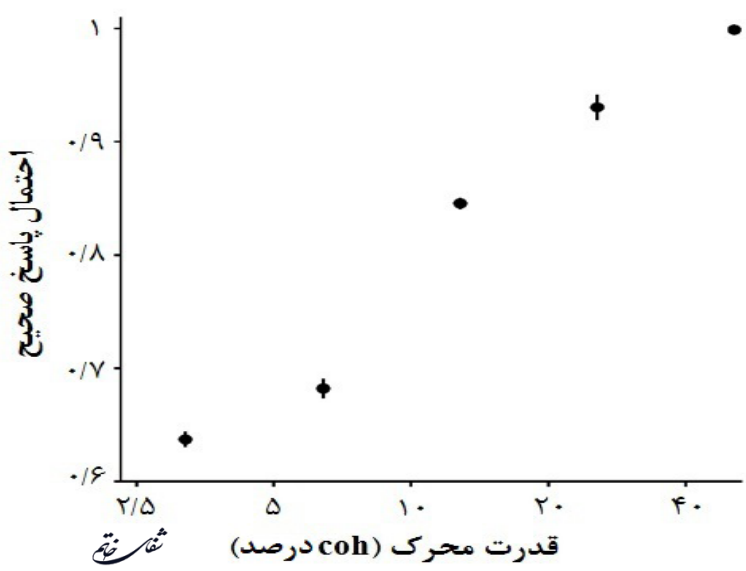

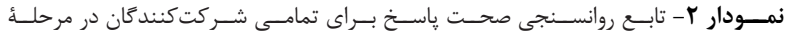

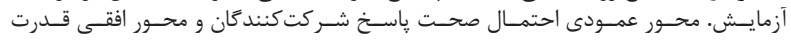

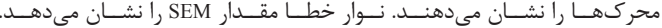

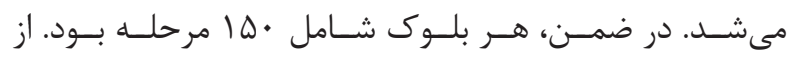

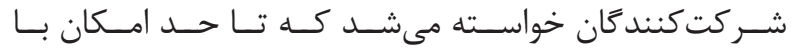

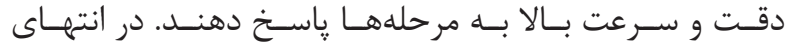

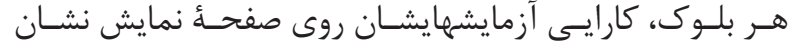

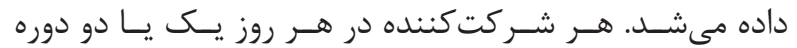

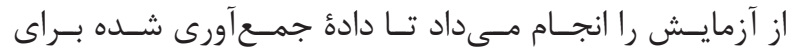

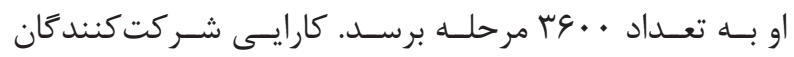

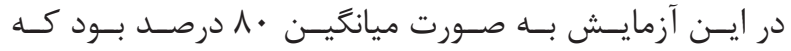

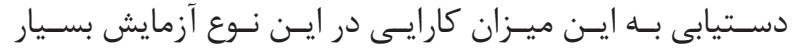

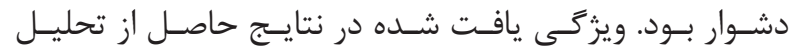

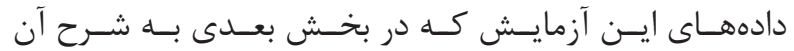

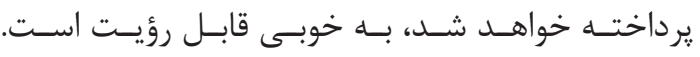

$$
\text { تحليل دادهها و بررسى آمارى }
$$

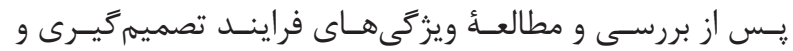

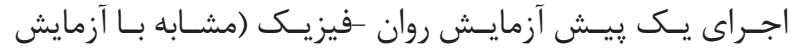

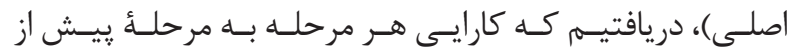

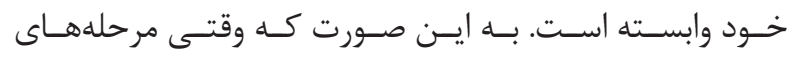

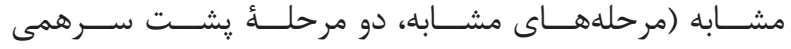

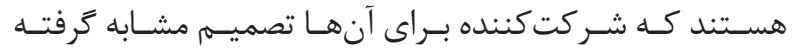

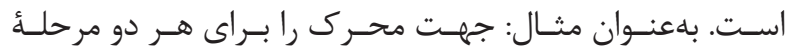

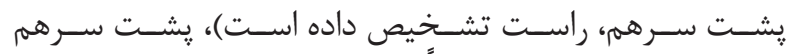

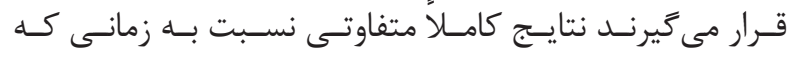

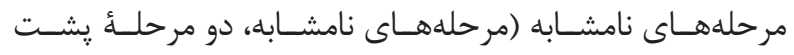

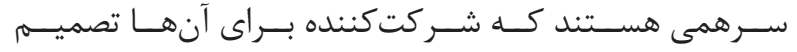

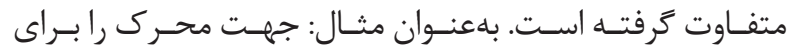

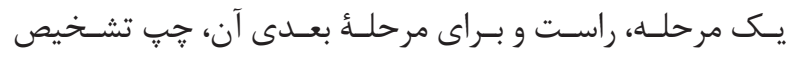

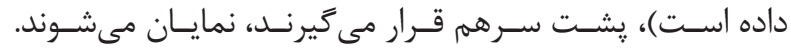

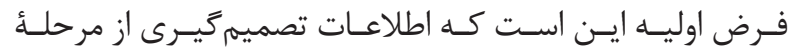

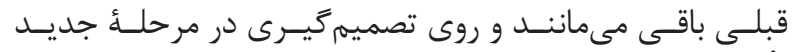

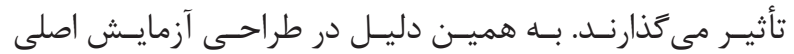

\footnotetext{
${ }^{35}$ Auditory feedback

${ }^{36}$ Beep
}

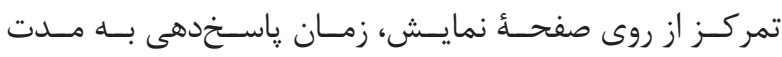

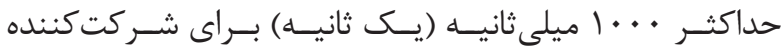

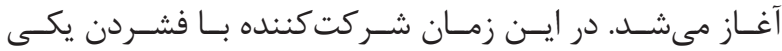

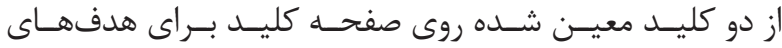

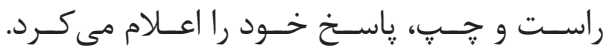

فيلبك

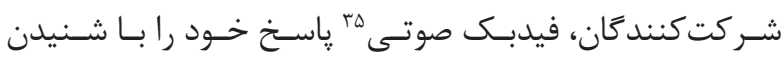

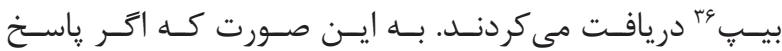

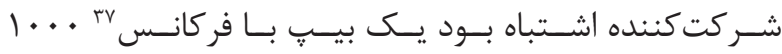

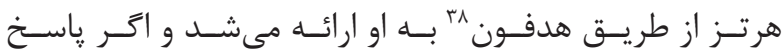

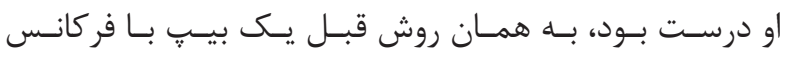

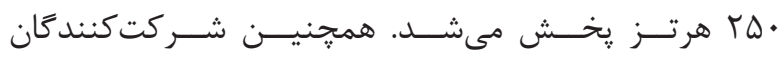

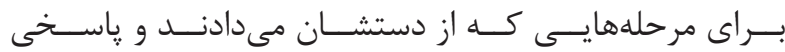

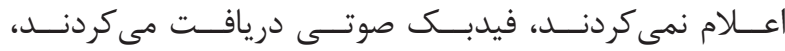

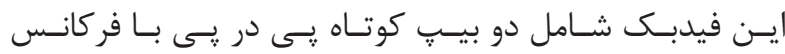

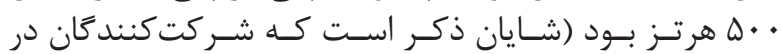

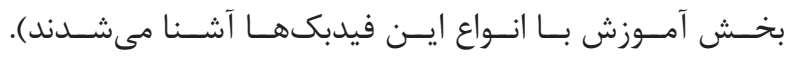

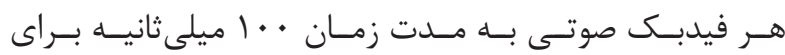

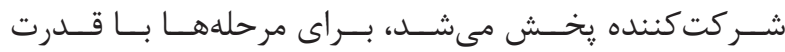

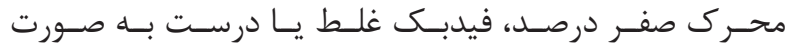

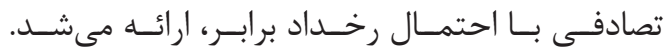

$$
\text { آزمايش رفتارى }
$$

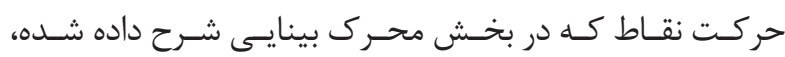

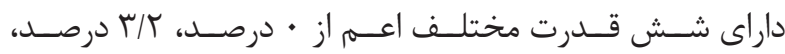

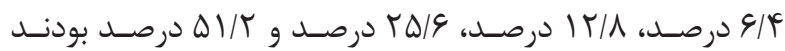

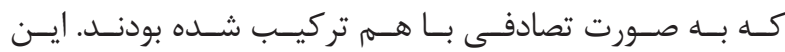

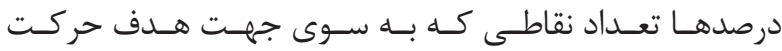

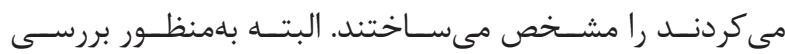

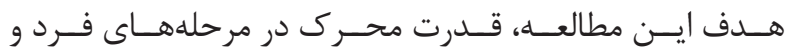

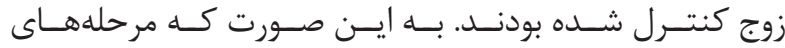

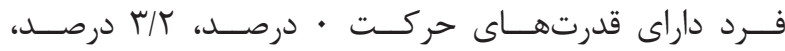

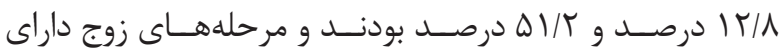

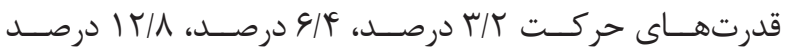

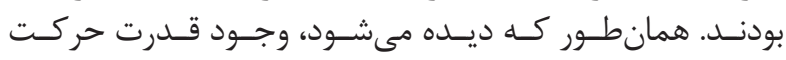

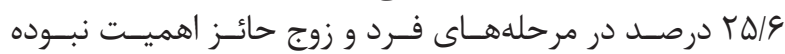

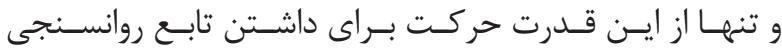

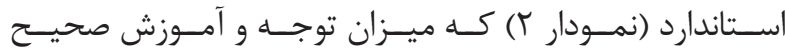

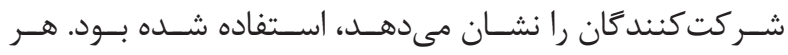

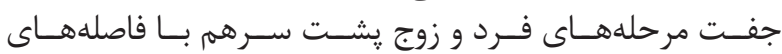

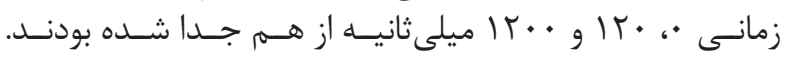

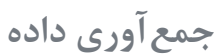

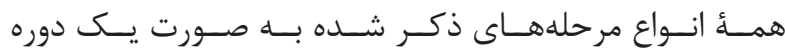

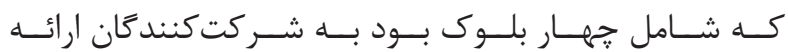

${ }^{37}$ Frequency
${ }^{38}$ Headphone 


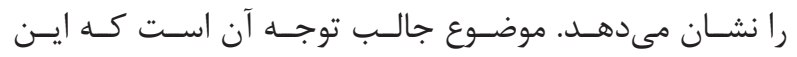

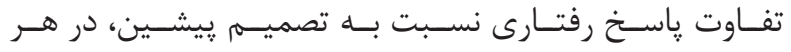

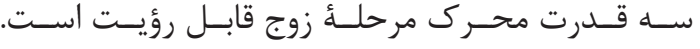

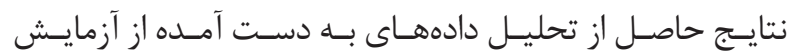

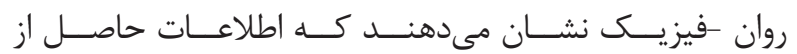

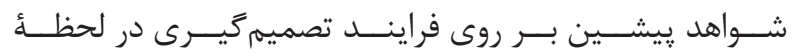

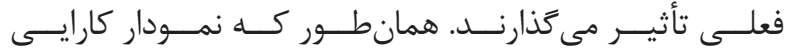

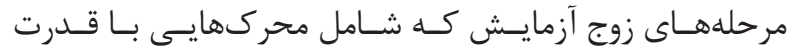

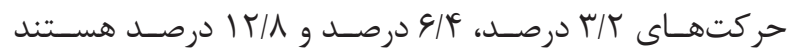

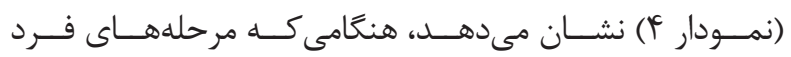

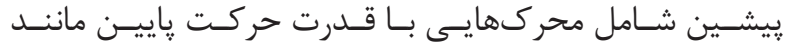

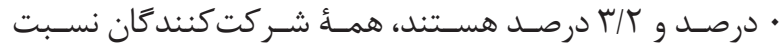

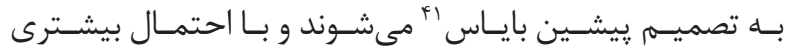

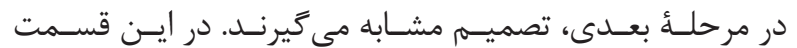

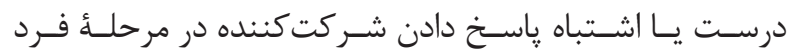

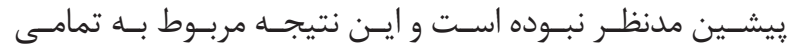

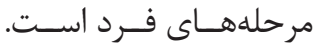

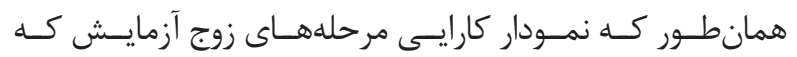

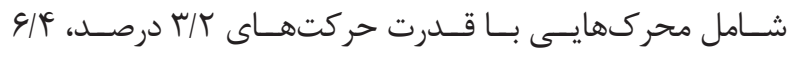

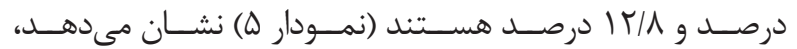

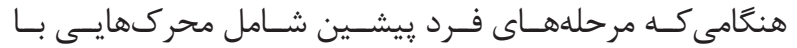

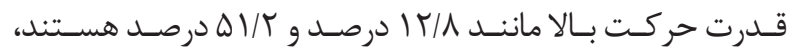

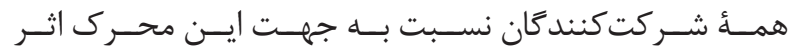

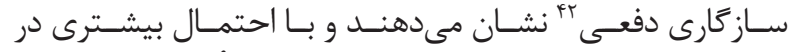

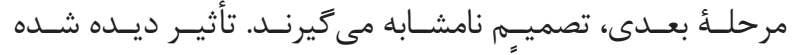

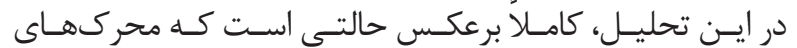

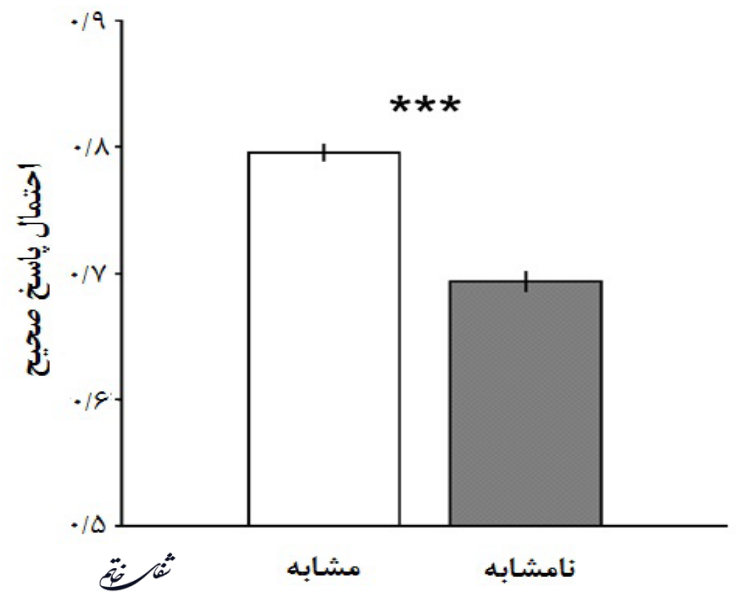

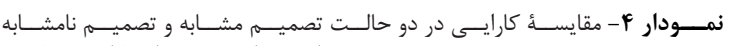

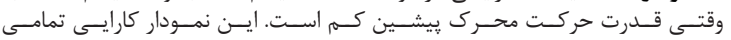

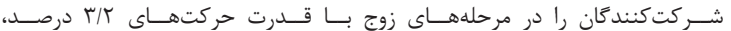

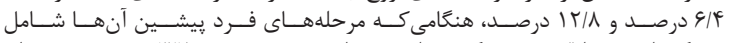

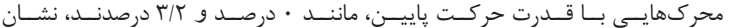

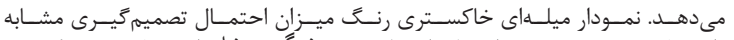

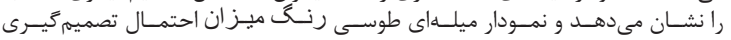

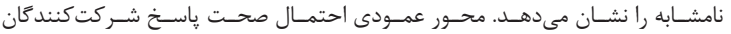

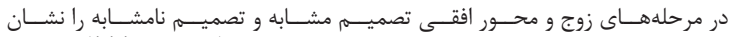

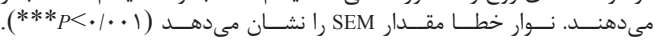

${ }^{39}$ Reset

${ }^{40}$ Wilcoxon rank sum test

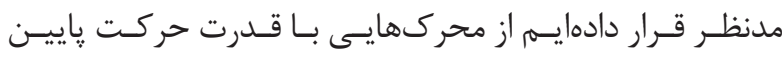

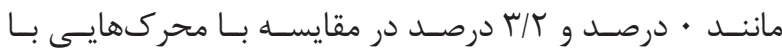

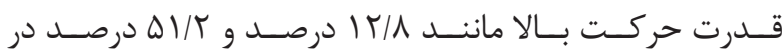

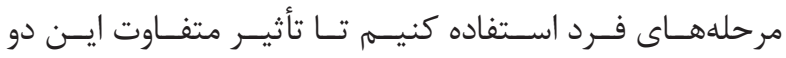

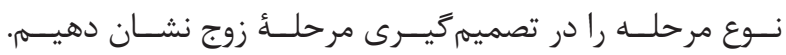

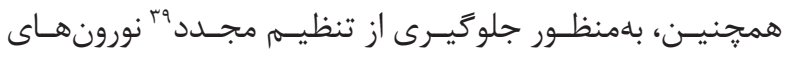

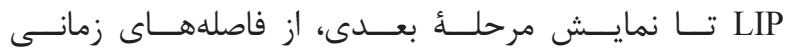

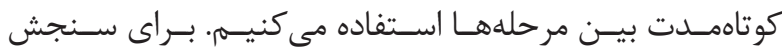

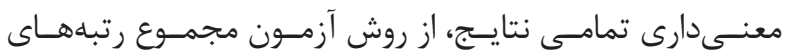

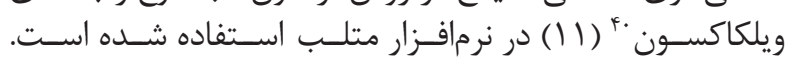

يافتهها

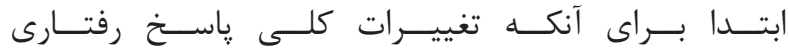

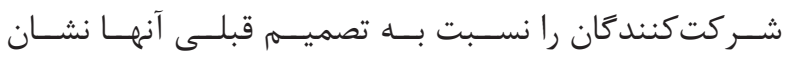

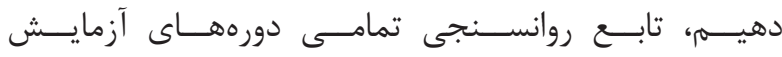

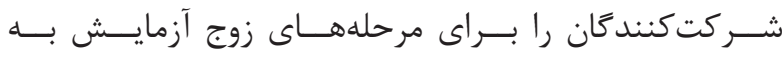

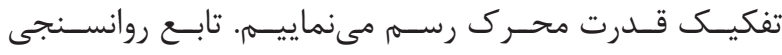

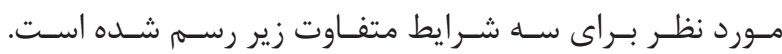

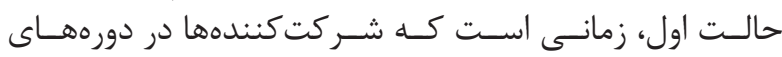

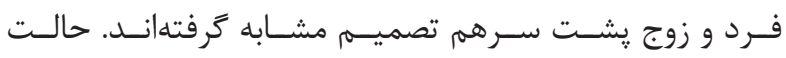

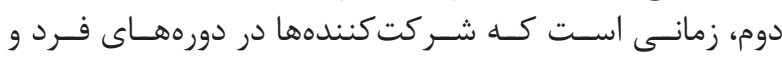

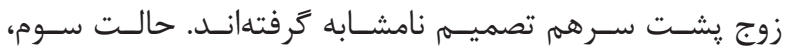

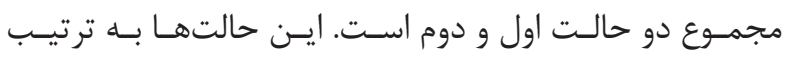

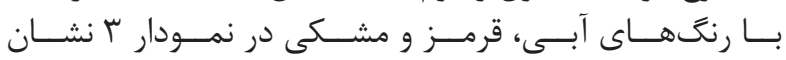

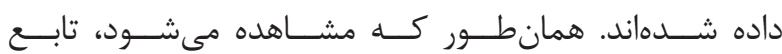

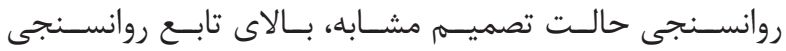

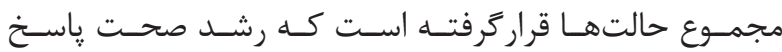

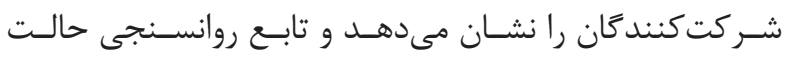

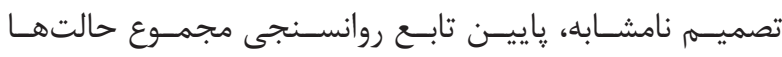

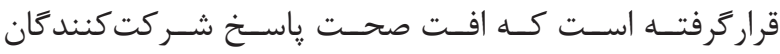

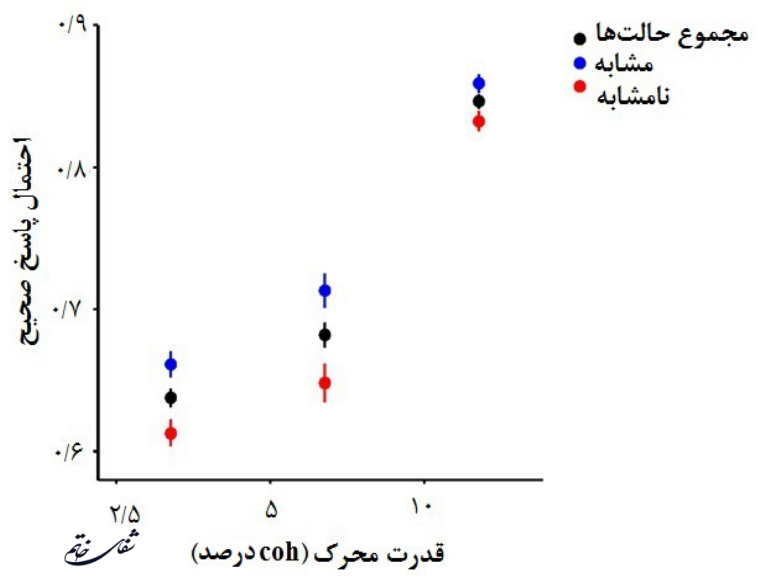

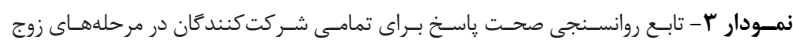

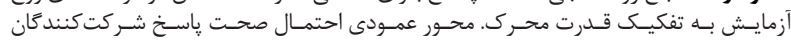

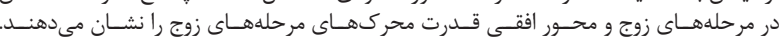

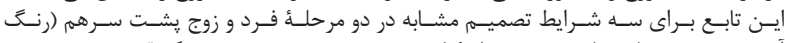

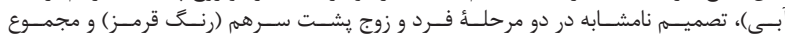

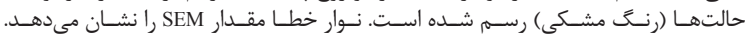

41 Bias

${ }^{42}$ Repulsive adaptation 


$$
\text { بحث و نتيجه }
$$

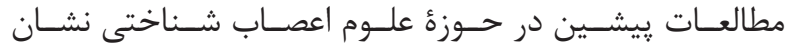

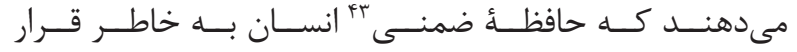

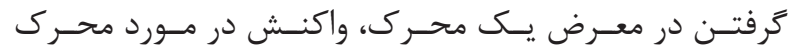

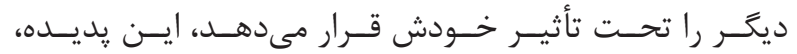

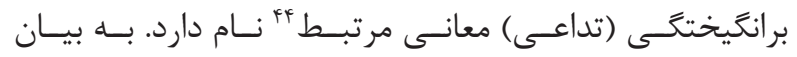

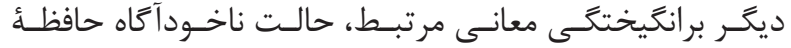

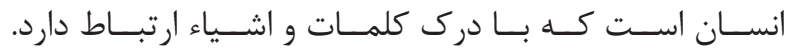

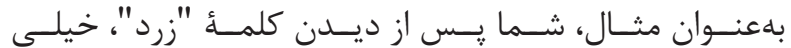

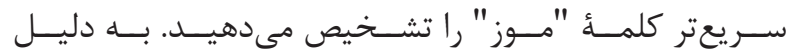

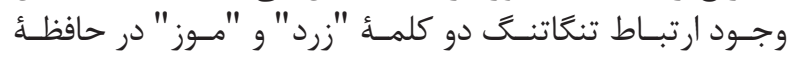

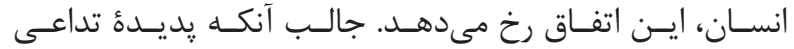

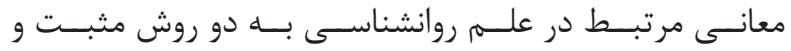

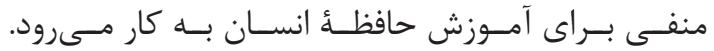

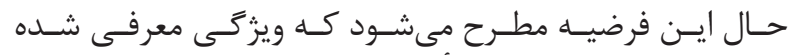

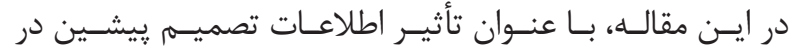

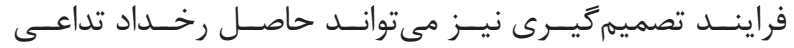

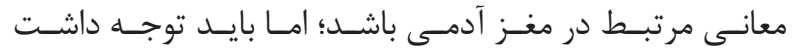

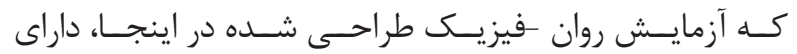

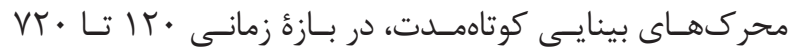

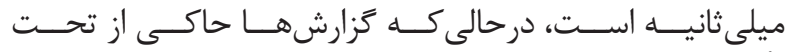

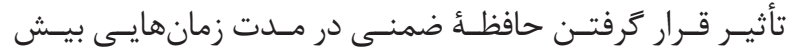

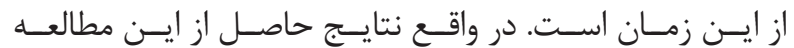

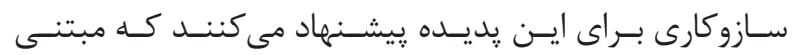

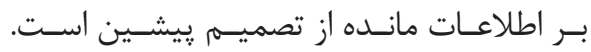

1. Mazurek ME, Roitman JD, Ditterich J, Shadlen MN. A role for neural integrators in perceptual decision making. Cereb Cortex. 2003; 13(11): 1257-69.

2. Lo CC, Wang XJ. Cortico-basal ganglia circuit mechanism for a decision threshold in reaction time tasks. Nat Neurosci. 2006; 9(7): 956-63.

3.RoitmanJD, ShadlenMN.Responseofneuronsinthelateral intraparietal area during a combined visual discrimination reaction time task. J Neurosci. 2002; 22(21): 9475-89.

4. Gold JI, Shadlen MN. The neural basis of decision making. Annu Rev Neurosci. 2007; 30: 535-74.

5. Ratcliff R. A theory of memory retrieval. Psychol Rev. 1978; 85(2): 59-108.

6. Smith PL, Ratcliff R. Psychology and neurobiology of simple decisions. Trends Neurosci. 2004; 27(3): 161-8.

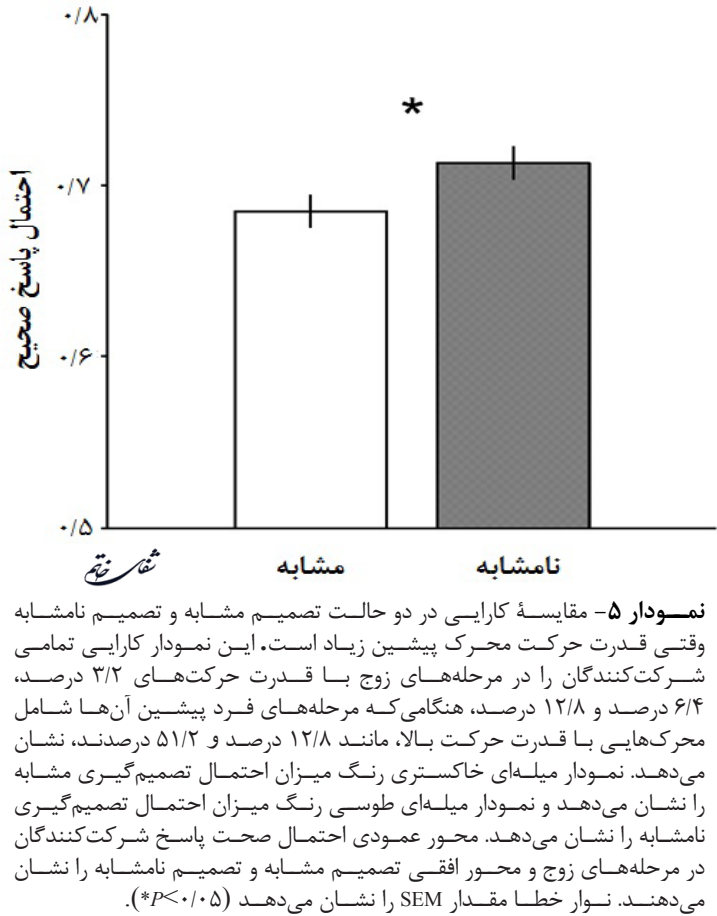

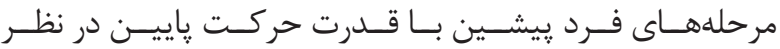

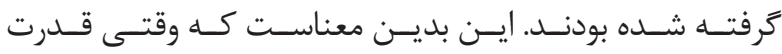

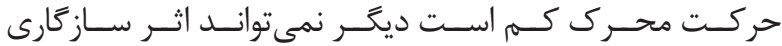

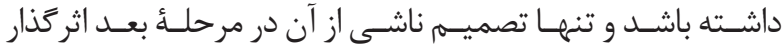

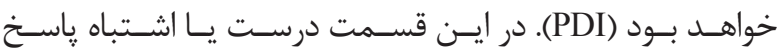

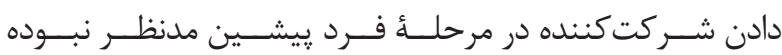

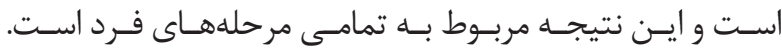

منابع

7. Gold JI, Shadlen MN. Neural computations that underlie decisions about sensory stimuli. Trends Cogn Sci. 2001; 5(1): 10-6.

8. Ditterich J. Stochastic models of decisions about motion direction: behavior and physiology. Neural Netw. 2006; 19(8): 981-1012.

9. Bogacz R, Brown E, Moehlis J, Holmes P, Cohen JD. The physics of optimal decision making: a formal analysis of models of performance in two-alternative forced-choice tasks. Psychol Rev. 2006; 113(4): 700-65.

10. Shadlen MN, Newsome WT. Neural basis of a perceptual decision in the parietal cortex (area LIP) of the rhesus monkey. J Neurophysiol. 2001; 86(4): 1916-36.

11. Kiani RC, Churchland AK, Shadlen MN. Integration of direction cues is invariant to the temporal gap between them. J Neurosci. 2013; 33(42): 16483-9.

\footnotetext{
${ }^{43}$ Implicit memory

${ }^{44}$ Priming
} 